\title{
Designing for Well-being and Healthcare Using Social Comparison
}

Vasiliki Mylonopoulou

University of Oulu

INTERACT Research Group

vasiliki.mylo@oulu.fi

\section{Minna Isomursu}

IT University of Copenhagen,

University of Oulu

INTERACT Research Group

miis@itu.dk

\section{Karin Väyrynen}

University of Oulu

INTERACT Research Group

karin.vayrynen@oulu.fi

\section{Abstract}

The aim of the workshop is to create a design

framework for social comparison (a social influence aspect / psychological theory). The social comparison theory supports that in lack of objective measurements, people compare themselves to others similar to them in order to evaluate their skills, abilities, and in general to understand better themselves. The framework will address a gap in current research focused on the design space of social comparison for health and wellbeing behavior change technologies. The workshop participants are invited to share their experiences and viewpoints on designing behavior change technology using social influence (the influence of others on once behavior). This can include, for example, practical cases or design ideas. These ideas will be consolidated through a framework skeleton pre-constructed by organizers through a literature review and past research.

\section{Author Keywords}

Design framework, Social comparison, health behavior change.

\section{ACM Classification Keywords}

Human-centered computing $~ \mathrm{HCI}$ design and evaluation methods. 


\section{Activities Layout}

\section{Discussion part:}

- D1: Participants and organizers discuss their experiences on design social influence features in health related applications.

- D2: Short presentation of the social comparison concept followed by discussion with participants and organizers

- D3: Short presentation of a framework skeleton followed by discussion with participants and organizers.

\section{Hands-on part:}

- H1: Design a health behavior change supportive technology - in a very primary stageusing social comparison, so they can reflect in practice on the discussions.

- H2: Reflect and discuss the use of the framework as a design aid for social comparison features in the health behavior change supportive technology.

\section{Short Description of the Workshop}

The proposed workshop provides an environment to share and exchange practical, methodological and theoretical perspectives on designing for behavior change. In particular, it looks at emerging - but less explored aspects - of using social comparison in design of health behavior change technological applications. By social comparison, we mean the comparison of one's data in relation to others for self-enhancement, selfevaluation, coping, support and motivation [3]. In the field of psychology, social comparison has been proven to have impact on wellbeing, coping and healthcare [1]. Victimized people (e.g. rape victims) cope better when they are in a group of people similar to them and they do not feel that they deviate [2]. Female breast cancer patients compare with patients worse than them to cope with their condition [5]. People who want to quit smoking have better possibilities on quitting by being in a group together with people who have easier time than themselves to quit, instead than being in a group with people who have harder time than them to quit [4]. However, there are not specific guidelines for designing social comparison features in technologies that support health behavior change.

The goal of the workshop is to create both practical and theoretical new knowledge as well as insights on how social comparison can be used to support health behavior change. This will be done through consolidating the input - of both participants and organizers - through co-creation activities into a design framework. The workshop will use a pre-defined social comparison design framework skeleton created by the organizers in order to guide the group work. The participants will bring in their personal experiences and viewpoints, and enrich the framework through interacting with it. The consolidation work will be done through a design case, where the aspect of social comparison will be studied through process of translating them into an actual design concept.

As a result, the workshop will generate an enriched social comparison design framework, which can be useful for both design practitioners and researchers exploring various aspects of design for behavior change. The goal is to publish the framework in HCI focused journal or conference.

\section{Benefits for the Participants}

The target audience of the workshop are researchers and design practitioners who are interested in use of behavior change techniques in health and wellbeing. The workshop will facilitate sharing of experiences on aspects that need to be considered when designing social influence features in technologies that support health behavior change, focusing on social comparison. This will result in a deeper understanding on Social Comparison theory and its different roles in health, wellbeing, and coping in life. The participants will take part in co-creation of a design framework, which addresses aspects of designing for social comparison, informed from four different perspectives: literature, healthcare professionals, designers, and users. The

collaborative work and sharing of experiences will provide opportunities for giving and receiving feedback in a constructive and supportive environment.

\section{Suggested Timetable}

The workshop will consist of two parts: the discussion part and the hands on part (see side bar). The 
- 09.30 Introduction of the workshop goals and participants introduction

09.30 - 10.45 Social influence for health behaviour change and design experiences D1

$10.45-\mathbf{1 1 . 1 5}$ Presentation of social influence aspects and introduction to social comparison D2

$11.15-13.30$ Lunch

13.30 - 14.30 Reflection on social comparison and brainstorming on cases the social comparison can be used $\mathbf{1 4 . 3 0} \mathbf{- 1 5 . 0 0}$ Presentation of the framework skeleton

$13.30-15.00$

Hands on design using the framework skeleton for the social comparison features: personas, H1 storyboards, paper mock-ups (use of digital if time allows it)

$15.00-15.30$

Break

$15.30-17.00$ Reflection and discussion on the design process by using the social comparison skeleton framework $H 2$

Table 1: Full-day timetable

suggested timetable for a full day workshop. However, as the size of the workshop will determine if the

workshop last a full day or half a day, we are keeping open the possibility to readjust the timetable so to occupy only half a day.

\section{Organizers' Committee}

The organizer committee consist of the following people:

- Vasiliki Mylonopoulou, PhD candidate, University of Oulu, INTERACT Research Group

- Minna Isomursu, Professor, IT University of Copenhagen and University of Oulu, INTERACT Research Group

- Karin Väyrynen, Ph.D. ,University of Oulu, INTERACT Research Group

\section{Organizers' Biographies}

Vasiliki Mylonopoulou is a PhD candidate and Marie Curie Fellow in INTERACT research unit at University of Oulu, Finland. Her background is in HCI and currently she works on health behavior change supportive technology that motivates people through visualizing their relation between their data and the data of others. The last three years she used a constructivist interpretivist approach and qualitative methodology to explore the different perspectives on social influence features in health behavior change supportive technological applications focused on social comparison in both theory and practice.

Minna Isomursu is a professor of Interaction and Codesign at IT university of Copenhagen, Denmark, and professor in Information systems at University of Oulu. Her research explores how the opportunities of digital technologies can be translated into services, which can create value for the ecosystem and society. Her special interests lie in the field of designing for and understanding the perceived experience of value, and design techniques to address the digital nature of services. During the last 10 years, her research projects have mainly examined use of digital technologies in health and wellbeing services. Professor Isomursu has organized workshops in scientific conferences and in research collaboration settings, for example, a workshop in Pervasive health 2018 conference. 


\section{Participation}

The participants voluntarily can write a short paper reflecting on their design experience related to social influence and health behavior change supportive technologies prior to the workshop. The papers will be shared with the participants and it will be their first contact. Participants with no papers will be able to participate and present their experience in the discussion section of the workshop.
Dr. Karin Väyrynen is a researcher in information systems. Her research focuses on communication and collaboration of global virtual teams, on the competitive potential of IT, connected health, and on the digitalization of the taxi industry and platformization. Her research has been published in Electronic Markets, the Journal of Organizational Computing and Electronic Commerce, and in international information system conferences such as the International Conference on Information Systems (ICIS) and the European Conference on Information Systems (ECIS). She has 12 years of teaching experience; she has conducted more than 40 credits of pedagogical studies, and run workshops in teaching and in the Enject COST action.

\section{Recruitment Strategy}

A workshop web page will be created at INTERACT web space hosted by University of Oulu web server. The workshop will be advertised through personal contacts and social media networks of organizers and their affiliations, such as LinkedIn, Facebook, Twitter etc. Additionally, internal mail lists and publications channels will be used to get participants from IT university of Copenhagen, University of Oulu, and their collaboration partners. Relevant mailing list such as COST action ENJECT mailing and AISworld mailing lists are used to reach targeted research participants. Additionally different channels will be explored to reach companies such as Centre for Health and Technology in Oulu that is a link between researchers and entrepreneurs.

\section{Acknowledgements}

This publication has received funding from the

European Union's Horizon 2020 research and innovation programme - Marie Sklodowska-Curie Actions grant agreement no. 676201 - CHESS - Connected Health Early Stage Researcher Support System.

\section{References}

1. Bram. Buunk and Frederick X. Gibbons. 2016. Health, coping, and well-being: perspectives from social comparison theory. Routledge.

2. Dan Coates and Tina Winston. 1983. Counteracting the Deviance of Depression: Peer Support Groups for Victims. Journal of Social Issues 39, 2: 169-194.

3. Festinger. 1954. A Theory of Social Comparison Processes. Human Relations 7, 2: 117-140.

4. Meg Gerrard, Frederick X Gibbons, David J Lane, and Michelle L Stock. 2005. Smoking cessation: social comparison level predicts success for adult smokers. Health psychology: official journal of the Division of Health Psychology, American Psychological Association 24, 6: 623-629.

5. Joanne V Wood, Shelley E Taylor, and Rosemary R Lichtman. 1985. Social Comparison in Adjustment to Breast Cancer. Journal of Personality and Social Psychology 49, 5: 1169-1183. 